\title{
KLASIFIKASI KAIN KHAS BATIK DAN KAIN KHAS SASIRANGAN DENGAN MENGGUNAKAN METODE CONVOLUTIONAL NEURAL NETWORK
}

\author{
Ihdalhubbi Maulida ${ }^{1)}$ \\ ${ }^{1)}$ Universitas Muhammadiyah Banjarmasin \\ Jalan S. Parman. Kompleks RS Islam, Pasar Lama, Banjarmasin Tengah, Kota Banjarmasin 70114 \\ e-mail: ihdal@umbjm.ac.id ${ }^{1)}$
}

\begin{abstract}
ABSTRAK
Di Indonesia terdapat 33 macam jenis kain khas, diantaranya adalah kain batik dan sasirangan. Kain batik dibuat dengan cara mempola, melukis menggunakan lilin yang sudah dicairkan, pewarnaan, membatik Kembali dan mencucinya untuk menghilangkan lapisan lilinya, sedangkan kain sasirangan yaitu dengan dijelujur dengan pola dan dicelupkan ke pewarna kain. Banyak jenis dari kain batik dan kain sasirangan sehingga tidak mudah membedakan yang mana kain sasirangan atau kain batik. Selain itu banyak bentuk pola batik yang hampir mirip dengan motif sasirangan. Pada kasus ini perlu dilakukan penelitian yang dapat mengklasifikasikan antara kain batik dan kain sasirangan agar masyarakat tidak menyamakan pola batik dengan pola sasirangan. Metode yang dipergunakan untuk melakukan klasifikasi ini yatu dengan model deep learning pada metode Convolution Neural Network (CNN). Deep Learning memiliki kemampuan sangat baik dalam melakukan klasifikasi objek pada sebuah citra dalam perkembangan teknologi GPU acceleration. Kemampuan klasifikasi yang dilakukan deep learning menerapkan metode CNN dengan dua tahap yaitu melakukan feedforward pada klasifikasi citra dan melakukan tahap pembelajaran menggunakan metode backpropagation. Sebelum melakukan dua tahap dari metode CNN tersebut perlu melakukan praproses yaitu dengan menerapkan metode wrapping dan cropping agar objek yang diklasifikasi dapat lebih terfokus dan selanjutnya metode feedforward dan backpropagation melakukan training. Setelah melakukan training maka dilakukan testing dengan metode feedforward dimana bobot dan bias diperbaharui sehingga menghasilkan akurasi sebesar 91,84\% dengan melakukan iterasi sebanyak 20 pada data training dan hasil akurasi pada saat melakukan testing sebesar $99,73 \%$.
\end{abstract}

Kata Kunci: Convolution Neural Network, Deep Learning, Kain Batik, Kain Sasirangan.

\begin{abstract}
In Indonesia there are 33 kinds of typical fabrics, including batik and Sasirangan fabrics. Batik cloth is made by patterning, painting using melted wax, staining, making batik back and washing it to remove the wax layer, while sasirangan cloth is by stripping it with a pattern and dipping it in cloth dye. Many types of batik fabrics and sasirangan fabrics so it is not easy to distinguish which fabric sasirangan or batik fabric. In addition, many forms of batik patterns are almost similar to sasirangan motifs. In this case, research needs to be done that can classify between batik cloth and sasirangan fabric so that people do not equate batik patterns with sasirangan patterns. The method used to do this classification is with deep learning model on Convolution Neural Network (CNN) method. Deep Learning has very good abilities in classifying objects an image in the development of GPU acceleration technology. Kemam-puan classification conducted deep learning apply CNN method with two stages, namely feedforward on image classification and conduct learning stage using backpropagation method. Before doing the two stages of the CNN method, it is necessary to preprocess by applying wrapping and crop-pinging methods so that classified objects can be more focused and then feedforward and backpropagation methods conduct training. After conducting training, testing with feedforward method where weight and bias are updated to produce accuracy of $91.84 \%$ by iterating as many as 20 on training data and accuracy results at the time of testing by $99.73 \%$.
\end{abstract}

Keywords: Batik Fabrics, Convolution Neural Network, Deep Learning, Sasirangan fabrics

\section{PEndahuluan}

$\mathrm{K}$

ain khas Indonesia yang diakui sebanyak 33 macam jenis telah terdaftar dalam warisan budaya tak benda oleh Kementerian Pendidikan dan Kebudayaan antara lain kain batik dan kain sasirangan [1]. Kain khas batik sangat terpopuler di Indonesia, sehingga di setiap acara resmi masyarakat banyak memakai kain batik. Motif batik dibuat dengan membuat corak atau pola yang dijadikan kerangka gambar dengan memadukan antara garis, bentuk dan isen menjadi satu kesatuan. Bentuk motif batik beragam ada yang berbentuk hewan, manusia, geometris, dan motif-motif lainnya[2]. Kain batik dibuat dengan cara menyiapkan kain mori, membuat desain batik, melukis di kain dengan menggunakan lilin yang sudah dicairkan, mengisi seluruh bagian putih pada kain dengan memberi warna pada pola dengan lilin, setelah itu beri warna kain pada bagian yang tidak diberi lilin, lukis kembali dengan canting, hilangkan lilin dan kembali membatik, hilangkan lapisan lilin agar motif terlihat jelas dan setelah semua proses, cuci kain batik dan jemur sampai kering [3]. 
Sasirangan merupakan kain adat suku Banjar di Kalimantan Selatan. Kain ini telah melalui tahap-tahap perizinan atau pengakuan Hak Kekayaan Intelektual (HKI) Departemen Hukum dan HAM RI. Sasirangan berasal dari kata menyirang. Nama ini sesuai dengan cara pembuatan Sasirangan, yang melalui proses menjelujur atau menyirang menggunakan perintangan dan pewarnaan. Bahan-bahan yang digunakan disesuaikan dengan corak yang akan dibuat, seperti tali, dan benang [4].

Kebanyakan orang menyamakan semua jenis kain dengan sebutan kain batik, padahal banyak perbedaan yang terdapat pada jenis kain tersebut. Dari hal tersebut maka perlu dilakukan penelitian yang bertujuan untuk dapat mengklasifikasikan kain batik dan kain sasirangan dengan menentukan akurasi tertinggi dari hasil model Deep Learning dalam algoritma Convolution Neural Network.

Metode Convolution Neural Network (CNN) menggunakan model deep learning yang mana mampu melakukan proses pembelajaran mandiri untuk pengenalan objek, ekstraksi objek dan klasifikasi serta dapat diterapkan pada citra resolusi tinggi yang memiliki model distribusi nonparametric [5] [6]. Penerapan metode CNN digunakan untuk mengenal pola motif kain tenun gringsing dengan model arsitektur alexnet yang mengatakan bahwa pengujian model yang dibangun mampu menyelesaikan training 100 epoch dengan waktu 19,33 jam dengan nilai akurasi sebesar $76 \%$, presisi sebesar 74,1\%, recall $72,3 \%$ dan F-measure sebesar 0,73 [7] [8].

\section{TINJAUAN PUSTAKA}

\section{A. Kain Batik}

Di Indonesia memiliki budaya seni yaitu kerajinan Batik yang berasal dari pulau jawa. Pada masa lampau, batik diolah menjadi keterampilan dengan nilai jual yang tinggi oleh perempuan jawa sebagai mata pencahariannya. Pada masa itulah membatik menjadi pekerjaan yang eksklusif. Tidak hanya perempuan saja yang melakukan membatik, akan tetapi laki-laki juga dapat melakukannya dengan menggunakan teknik batik cap. Beda halnya dengan kegiatan membatik pada daerah pesisir yang mana pekerjaan membatik dilakukan oleh laki-laki. Daerah pesisir memiliki corak yang disebut dengan "Mega Mendung" yang memiliki ciri khas yaitu garis maskulin pada corak dan hanya dilakukan oleh laki-laki. Kegiatan membatik juga dilakukan secara turun menurun dari berbagai keluarga sehingga tradisi tersebut dikenal dengan batik keluarga. Motif motif dari tradisi keluarga ini mampu menunjukan kasta atau status seseorang pada suatu daerah. Banyak dari motif motif tradisi keluarga dipakai oleh keluarga keraton Yogyakarta dan Surakarta [9]. Berdasarkan dari sejarah kain batik, dapat disimpulkan bahwa kain batik memiliki kekhasan yang berbeda dari dari setiap daerah yang merupakan bentuk tradisi yang sudah dijalankan turun menurun sampai dengan sekarang dan kekhasan motifnya menjadikan kain batik menjadi kain nasional Indonesia.

Adapun cara pengolahan kain batik yaitu: (1) Bahan batik yaitu kain mori berwarna putih yang berasal dari kapas. Kain untuk batik bisa juga berasal dari suteram polister, rayon dan bahan sintesis lainnya (2) Motif batik dibuat dengan lilin yang dicairkan dan dimasukan ke dalam canting untuk membuat motif halus dan dapat menggunakan kuas pada bentuk motif yang lebih besar sehingga cairan lilin dapat terserap pada serat kain. (3) Hasil dari kain yang sudah dilukis dengan lilin akan dicelupkan sesuai dengan warna yang akan dimasukan pada motif batik. Penggunaan warna diawali dengan warna yang muda. (4) Motif lain akan diberi warna lebih tua atau gelap. (5) Lakukan kegiatan 3 dan 4 disesuaikan dengan motif yang terlah dibuat. (6) Setelah pewarnaan selesai, kain batik dicelupkan pada larutan kimia sehingga lilin menjadi larut [9]. Kegiatan membatik diatas merupakan kegiatan batik secara manual atau biasa disebut dengan batik tulis. Pembuatan batik tulis membutuhkan waktu kurang lebih 2-3 bulan. sedangkan untuk batik yang dibuat dengan menggunakan bahan tembaga membutuhkan waktu kurang lebih 2-3 hari kegiatan membatik dengan bahan tembaga ini disebut dengan batik cap. Hasil dari batik cap tidak sebagus dengan batik tulis dikarenakan menggunakan bahan tambahan menjadikan kurangnya jenis motif atau banyak motif yang sama dari 1 kain dengan kain yang lain.

\section{B. Kain Sasirangan}

Provinsi Kalimantan Selatan merupakan provinsi dari bagian kepulauan Kalimantan. Provinsi Kalimantan Selatan memiliki banyak adat dan budaya yang masih murni, misalnya ada Suku Dayak yang berada pada pegunungan Meratus. Selain suku, Kalimantan Selatan juga mempunyai banyak sungai sehingga mendapatkan gelar sebagai pulau seribu sungai. Tidak hanya suku dan budaya yang khas saja di Kalimantan Selatan akan tetapi masyarakat Kalimantan Selatan juga memiliki kegiatan mengolah kain yang bermotif untuk dijadikan kain khas Kalimantan Selatan yang disebut kain sasirangan.

Kain sasirangan di Kalimantan Selatan memiliki kekhasan yaitu dengan Teknik menjelujur untuk mengolah motif dari kain sasirangan. Masyarakat Kalimantan Selatan awalnya mempercayai bahwa kain sasirangan ini dapat mengobati penyakit dan mengusir roh jahat sehingga hanya masyarakat tertentu saja yang boleh membuatnya dan dari hal itulah kain sasirangan menjadi sangat langka atau jarang dibuat. Pembuatan kain sasirangan masih menggunakan alat tradisional [10].

Berikut ini motif motis sasirangan yaitu Sari Gading, Kangkung Kaokamban, Gigi Haruan, Daun Jeruju, Kembang kacang Tradisional, Tampuk Manggis, Hiris Pudak, Kembang Sakaki, Bayam Raja, Ombak Sinapur Karang, Naga Balimbur, Bintang, Jajumputan, Daun Katu, Gradasi, Langsat, Naga, Laba-laba, Dara Menginang, Bakantan, Pasar Terapung dan Ketupat [12].

\section{Deep Learning}

Teknik machine learning yang dapat memanfaatkan layer yang banyak dalam mengolah informnasi secara non linier yaitu Teknik Deep Learning. Deep Learning dapat melakukan ekstraksi fitur sehingga dapat mengolah data pola dan mendapatkan hasil dari klasifikasi dari data citra yang diolah. Pada Teknik deep learning,pemecahan masalah pada suatu citra memanfaatkan 
Teknik neural network [14]. Sehingga Teknik deep learning sangat dianjurkan untuk memecahkan masalah pada pencitraan yang mana Teknik ini mampu mengolah ekstrksi fitur kedalam sebuah data dan dapat melakukan klasifikasi.

\section{Convolutional Neural Network}

Convolutional Neural Network (CNN) merupakan multilayer Perceptron (MLP) yang dikembangkan dengan mengolah data dua dimensi dalam membentuk citra yang termasuk dalam Deep Natural Network. Deep Natural Network mempunyai kedalam jaringan yang tinggi dan pada data citra dapat diaplikasikan. Klasifikasi citra dapat menggunakan MLP tetapi penggunaan metode MLP ini tidak dapat menyimpan informasi spasial dari data citra sehingga dianggap setiap piksel adalah fitur yang independent mengakibatkan hasil dari klasifikasi menjadi kurang baik. Penelitian yang menemukan CNN ini untuk pertama kali dilakukan oleh Hubel dan Wiesel tentang visual cortex pada indera penglihatan kucing [13].

Pada pengembangannya Convolutional Neural Network (CNN) memanfaatkan teknik deep learning sebagai machine learning yang mana pada teknik deep learning dapat mengajarkan computer sesuai dengan pekerjaan yang dilakukan oleh manusia. Sehingga pada prosesnya Teknik deep learning ini dapat melakukan training data dari computer[14]. Berdasarkan dari kegiatan deep learning maka CNN dapat melakukan operasi konvolusi yang mampu menggabungkan beberapa lapisan proses enggunakan beberapa elemen yang dioperasikan secara paralel dan mampu menginspirasi system saraf biologis.

Presentasi dari CNN pada setiap neuron membentuk 2 dimensi, sehingga metode ini cocok untuk pemrosesan dengan input berupa citra [15] [16].

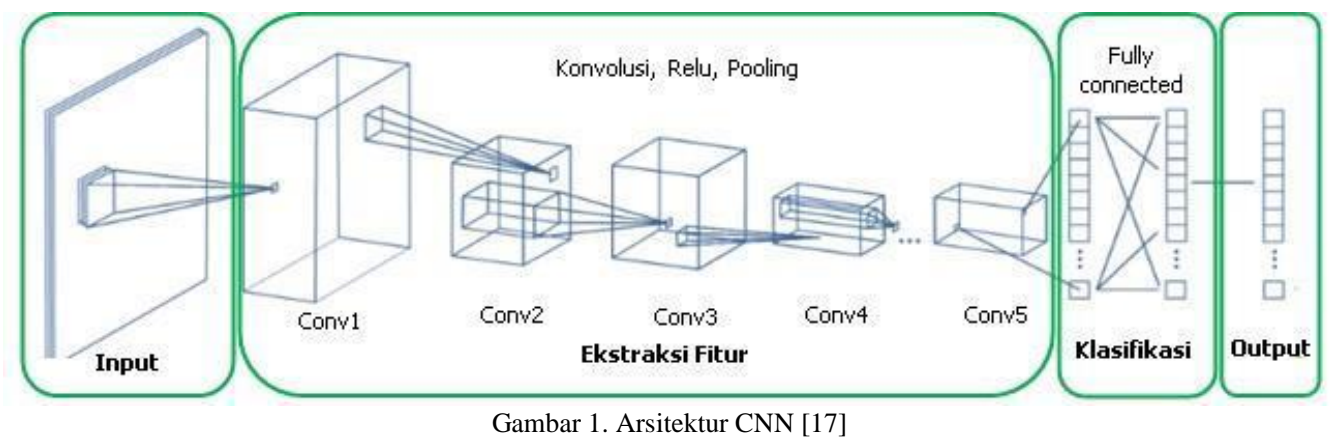

\section{E. Lapisan Konvolusi}

Filter untuk mengekstraksi objek yang berasal dari citra input yang mana filter itu memiliki bobot yang difungsikan sebagai deteksi karakter dari sebuah objek dapat berupa tepi, kurva atau warna adalah proses lapisan konvolusi yang ada pada CNN. Lapisan konvolusi ini akan menghasilkan transformasi linier yang berasal dari citra input yang menyesuaikan dengan informasi spasial pada data. Proses filter yang berulang dapat menghasilkan serangkaian bidang receptive. Parameter yang digunakan untuk dapat memodifikasi dari sifat pada setiap lapisan yaitu dengan mengubah ukuran filter, melakukan control filter dengan menentukan data input yang bergerak sepanjang piksel atau bisa disebut dengan pengendalian stride, dan melakukan padding yang pada proses ini yaitu menambahkan ukuran pixel dengan nilai tertentu pada sekitaran data input agar mendapatkan hasil receptive yang tidak terlalu kecil sehingga informasi yang didapat tidak banyak yang hilang.

Nilai padding biasanya nol maka padding itu disebut dengan zero padding. Hasil dari bidang receptive berupa data tunggal. Output dari proses konvolusi ini dijadikan sebagai input untuk lapisan konvolusi selanjutnya [18].

Operasi konvolusi sebagai berikut :

$s(t)=(x * t)(t)=\sum_{\alpha=-\infty}^{\infty} x(\alpha) * w(t-a)$

Keterangan :

$\mathrm{s}(\mathrm{t}) \quad=$ Fungsi hasil operasi konvolusi

$\mathrm{x} \quad=$ input

$\mathrm{W} \quad=$ bobot

Hyperparameters digunakan untuk menentukan volume output yang ditentukan dari masing masing lapisan. Perhitungan banyaknya neuron aktivasi dalam sekali output pada hyperparameters dapat dilihat dari persamaan dibawah ini:

$(W-F+2 P) /(S+1)$

Keterangan :

$\mathrm{W}=$ ukuran volume gambar

$\mathrm{F} \quad=$ ukuran filter

$\mathrm{P} \quad=$ Nilai Padding yang digunakan 
S = ukuran pergeseran (Stride)

\section{F. Fungsi Aktifasi ReLU}

ReLU (Rectification Linear Unit) adalah operasi yang dapat mengenalkan nonlinearitas dan meningkatkan representasi dari model. Fungsi aktivasi ReLU adalah $\mathrm{f}(\mathrm{x})=\max (0, \mathrm{x})$ [19]. Nilai hasil output pada neuron dinyatakan sebagai 0 apabila nilai input adalah negative dan apabila nilai input adalah positif, maka output dari neuron adalah nilai input aktivasi itu sendiri [20].

\section{G. Pooling}

Pooling atau subsampling yaitu pengurangan ukuran matriks, ada dua macam pooling yang sering digunakan yaitu average pooling dan max pooling [21]. Nilai yang diambil pada average pooling adalah nilai rata-rata sedangkan pada max pooling adalah nilai maksimal [22]

\section{H. Fully Cyonnected Layer}

Proses konvolusi yang dikumpulkan merupakan Lapisan fully connected yang mana Lapisan ini didapat dari proses input sebelumnya sebagai penentu fitur yang paling berkolerasi pada kelas tertentu. Berdasarkan itu fungsi dari lapisan ini adalah sebagai penyatu semua node menjadi satu dimensi [23].

\section{Metodologi PENELITIAN}

\section{A. Populasi dan Sampel}

Populasi dalam penelitian ini adalah citra kain batik dan kain sasirangan dengan semua jenis pola yang diambil dari pencarian google. Citra Kain batik dan citra kain masing-masing sebanyak 35 sebagai sampelnya.

\section{B. Jenis dan Sumber Data}

Jenis data yang digunakan merupakan jenis data primer yang mana data tersebut diambil dari pencarian google. Untuk kajian penelitian diperoleh dari jurnal, buku dan website pendukung.

\section{Tahap Penelitian}

Tahap penelitian sebagai berikut ini.

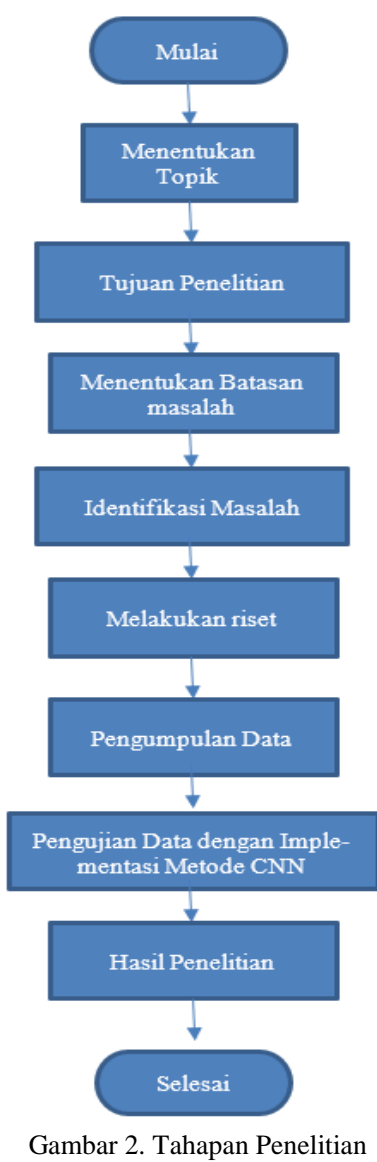




\section{HASIL DAN PEMBAHASAN}

\section{A. Persiapan Data}

Pada penelitian disiapkan data sebanyak 70 buah data yang mana terdiri dari 35 data citra dari kain batik dan 35 buah data dari citra kain sasirangan.

\section{B. Proses Training}

Dari data sebanyak 70 buah, diuji datanya sebanyak 20 buah secara random seperti gambar dibawah ini :
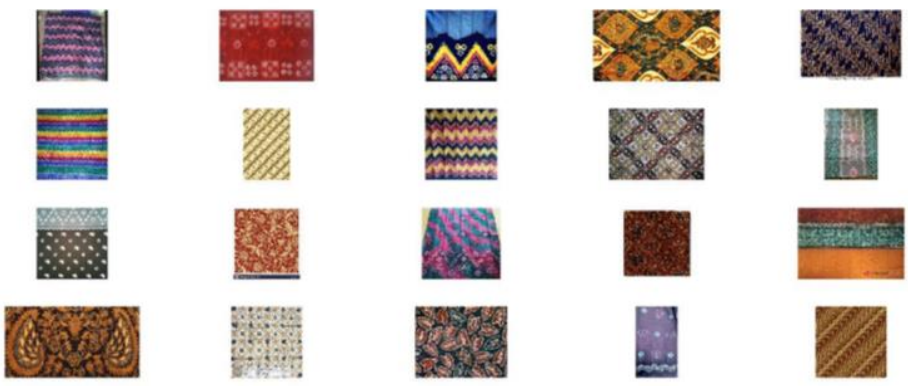

Gambar 3. Data Training

Setelah data training disiapkan, maka data training akan dilakukan pengujian dengan memberikan epoch 20 dan layer-2 maka yang didapat yaitu akurasinya sebesar 91.84\% dengan Loss sebesar 0.1603 .
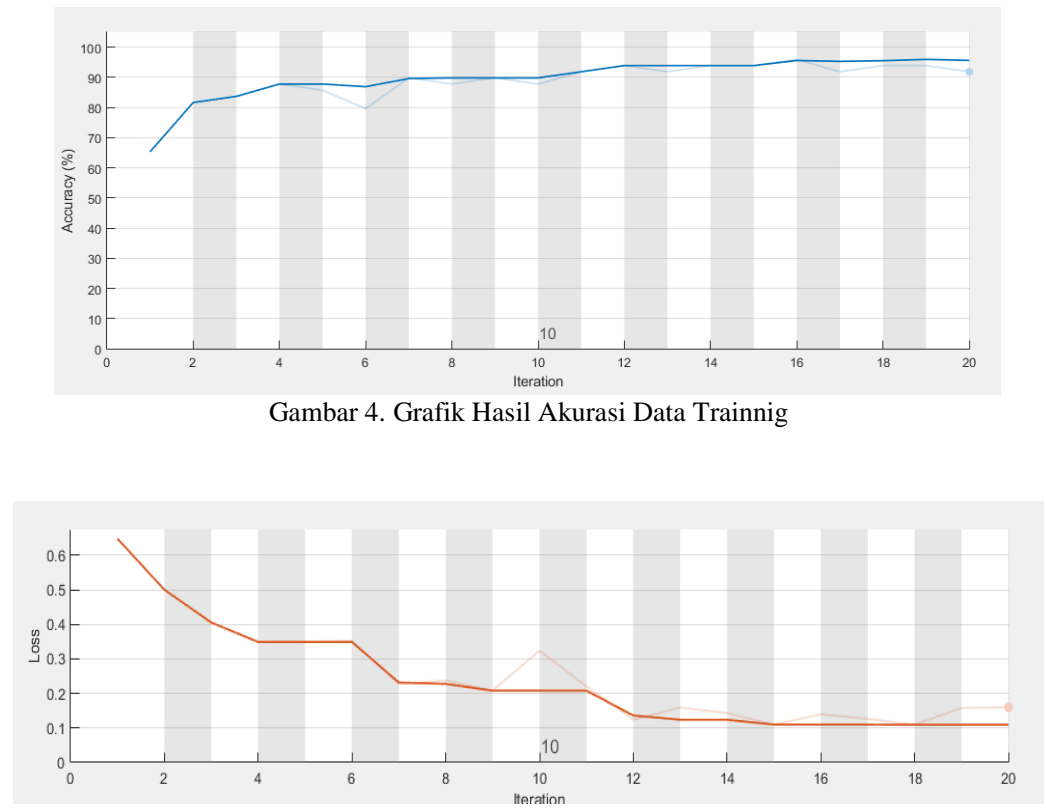

Gambar 5. Grafik Hasil Loss Data Trainnig

\section{Proses Testing}

Setelah melakukan training, maka data akan diuji Kembali dengan data citra acak sebanyak 20 buah dan menjadikan satu sampel gambar untuk diuji akurasinya. Dari hasil pengujian tersebut didapatkan hasil akurasi sebesar $99,73 \%$ yang dapat dilihat pada gambar 6 .
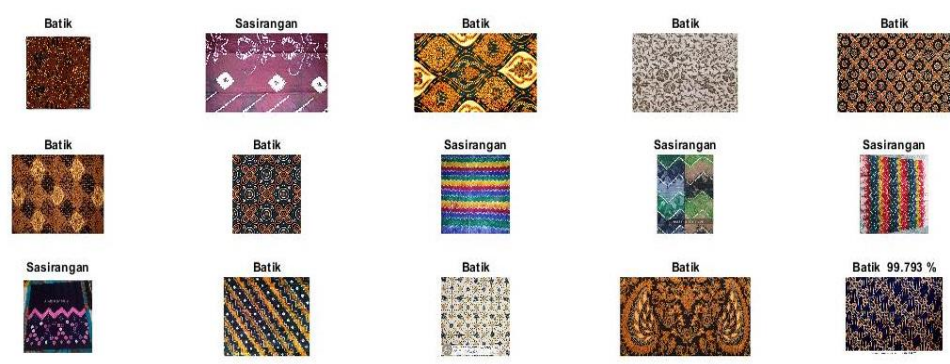

Gambar 6 Data Testing 


\section{KESIMPULAN}

Metode CNN memiliki dua tahapan yaitu melakukan klasifikasi citra dengan feed forward dan melakukan tahapan pembelajaran yang mana pada tahap pembelajaran CNN menerapkan metode backpropagation. Proses klasifikasi yang dilakukan harus melewati praproses yang mana menerapkan metode wrapping dan cropping dengan tujuan untuk memfokuskan objek untuk dapat diklasifikasi. Selanjutnya melakukan training dengan menggunakan metode feed forward dan backprogation. Dan tahap akhir yaitu tahap klasifikasi dengan menerapkan metode feedforward yang nilai bobot dan nilai bias sudah diperbaharui. Setelah melakukan hasil tersebut didapat hasil akurasi sebesar 91,84\% pada saat ditraining dengan melakukan data random dengan epoch sebanyak 20 dan saat melakukan pengujian data dengan data random sebanyak 10 data maka didapat hasil akurasi sebanyak $99.73 \%$.

\section{DAFTAR PUSTAKA}

[1] R. Indra, "33 Kain Tradisional Ditetapkan Jadi Warisan Budaya," CNN Indonesia, Jakarta, 2017.

[2] H. Nugroho, "Pengertian Motif Batik dan Filosofinya," Kementerian Perindustrian Republik Indonesia, 28 Februari 2020. [Online]. Available: https://bbkb.kemenperin.go.id/index.php/post/read/pengertian_motif_batik_dan_filosofinya_0. [Accessed 09 Febuari 2021].

[3] N. M. Sari, "https://hot.liputan6.com/read/4124194/10-cara-membuat-batik-tulis-mudah-dipraktikkan-untuk-pemula," Liputan 6, 02 Desember 2016. [Online]. Available: https://hot.liputan6.com/read/4124194/10-cara-membuat-batik-tulis-mudah-dipraktikkan-untuk-pemula. [Accessed 09 Febuari 2020].

[4] I. R. Nidya, "https://regional.kompas.com/," Kain Sasirangan, Oleh-oleh yang Bisa Dibawa Pulang dari Banjarmasin, 24 Januari 2020. [Online]. Available: https://regional.kompas.com/read/2020/01/24/18374491/kain-sasirangan-oleh-oleh-yang-bisa-dibawa-pulang-dari-banjarmasin?page=all [Accessed 09 Febuari 2021].

[5] C. Zhang, I. Sargent, X. Pan, A. Gardiner, J. Hare and P. M. Atkinson, "VPRS-Based Regional Decision Fusion of CNN and MRF Clasification for very Fine Resolution Remotely Sensed Images," IEEE Transactions on Geoscience and Remote Sensing, no. http://doi.org/10.1109/TGRS.2018.2822783, pp. 1-15, 2018.

[6] E. N. Arrofiqoh and H. , "Implementasi Metode Convolutional Neural Network Untuk Klasifikasi Tanaman Pada Citra Resolusi Tinggi," Geomatika, vol. Vol. 24 No 2, no. http://dx.doi.org/10.24895/JIG.2018.24-2.810, 2018.

[7] P. A. Wicaksana, I. M. Sudarma and D. C. Khrisne, "Pengenalan Pola Motif Kain Tenun Gringsing Menggunakan Metode Convitional Neural Network Dengan Model Arsitektur Alexnet," Jurnal Spektrum, vol. Vol 6 No 3, p. 159, 2019.

[8] M. A. Rasyidi and T. Bariyah, "Batik Pattern Recognition using Convolutional Neural Network," Bulletin of Electrical Engineering and Informatics, vol. Vol. 09 No. 4, no. ISSN: 2302-9285, DOI: 10.11591/eei.v9i4.2385, p. 1430, 2020

[9] "id.Wikipedia.org," [Online]. Available: https://id.wikipedia.org/wiki/Batik. [Accessed 10 Februari 2021].

[10] A. Pratomo, E. Najwaini, A. Irawan and M. Risa, "Optimasi E-Commerce dengan Penerapan Teknik SEO(Search Engine Optization) untuk Meningkatkan Penjualan Pada UKM Nida Sasirangan," Jurnal Impact : Implementation and Action, vol. Vol 1 No 01, pp. 35-47, 2018.

[11] Z. Almas, "Nilai-Nilai dalam Motif Kain Sasirangan," jurnal Socius, vol. Vol 07 No 2, pp. 210-220, 2018.

[12] D. L and Y. D. , "Deep Learning: Methods and Aplications Foundations and Trends R in Signal Processing," Foundations and Trends in Signal Processing, vol. Vol. 7, pp. 3-4, 2013.

[13] D. Hubel and T. Wiesel, "Receptive Fields and Functional Architecture of Monkey Striate Kortex," Jornal of Physiology, vol. 195, pp. 215-243, 1968.

[14] E. Maggiori, Y. Tarabalka, G. Charpiat and P. Alliez, " Convolutional Neural Networks for LargeScale Remote-Sensing Image Classification," IEEE Transactions on Geoscience and Remote Sensing, vol. 55(2), no. https://doi.org/10.1109/TGRS.2016.2612821, pp. 645-657, 2016.

[15] A. Katole, K. P. Yellapragada, A. K. Bebi, S. S. Karla and M. Siva Chaitanya, "Hierarchical Deep Learning Architure for 10K Objects Classification," Computer Science \& Information Technology (CS \& IT), vol. September, no. https://doi.org/10.5121/csit.2015.51408, pp. 77-93, 2015.

[16] A. Krizhevsky, I. Sutskever and G. E. Hinton, "ImageNet Classification with Deep Convolutional Neural Networks," Proceedings of The Twenty-Sixth Annual Conference on Neural Information Processing Systems, Vols. 3-8 December 2012, pp. 1097-1105, 2012.

[17] M. Castelluccio, G. Poggi, C. Sansone and L. Verdolia, "Land Use Clasification in Remote Sensing Images by Convolutional Neural Networks," 11 Agustus 2015. [Online]. Available: https://arxiv.org/pdf/1508.00092.pdf. [Accessed 10 Febuari 2021].

[18] J. Heaton, Artificial Intelligence for Humans: Deep Learning and Neural Networks of Artificial Intelligence for Humas Series, Createspace Independent Publishing Platform, 2015.

[19] J. Kim, O. Sangjun, Y. Kim and M. Lee, "Convolutional Neural Network with Biologically Inspired Retinal Structure,", Procedia Computer Science, vol. Vol 88, no. https://doi.org/10.1016/j.procs.2016.07.418, pp. 145-154, 2016.

[20] B. M. Belete, A. N. A. M. and F. , "A Convolutional Neural Network Approach for Assisting Avalanche Search and Rescue Operations with UAV Imagery," Remote Sensing, vol. Vol 09 No 02, no. https://doi.org/10.3390/rs9020100, p. 100, 2017.

[21] T. Zhi, L. Duan, Y. Wang and T. Huang, "Two-stage pooling of deep convolutional features for image retrieval," IEEE International Conference on Image Processing (ICIP), no. doi: 10.1109/ICIP.2016.7532802, pp. 2465-2469., 2016.

[22] S. Albelwi and A. Mahmood, "A Framework for Designing the Architectures of Deep Convolutional Neural Networks," Entropy, vol. 242 , p. 19, 2017.

[23] Y. F. Andriana, "Pergeseran Fungsi dan Makna Simbolis Kain Sasirangan," Jurnal Rupa, vol. Vol 03 Edisi 2 No 01, pp. 77-92, 2018. 